\title{
Financial Integration and Risk-Adjusted Growth Opportunities
}

Gianni De Nicolò and Iryna Ivaschenko 



\title{
IMF Working Paper
}

\author{
Research Department
}

Financial Integration and Risk-Adjusted Growth Opportunities

\section{Prepared by Gianni De Nicolò and Iryna Ivaschenko}

Approved by Krishna Srinivasan

May 2008

\section{This Working Paper should not be reported as representing the views of the IMF. The views expressed in this Working Paper are those of the author(s) and do not necessarily represent those of the IMF or IMF policy. Working Papers describe research in progress by the author(s) and are published to elicit comments and to further debate.}

\begin{abstract}
This paper documents the evolution of measures of financial integration for major advanced and emerging markets economies, assesses whether advances in integration have had a significant positive impact on countries' risk-adjusted growth opportunities, and identifies some of the channels through which financial integration may foster growth. Three main results obtain. First, financial integration has progressed significantly worldwide, particularly in emerging markets, and regional integration has advanced at the fastest pace in Europe. Second, a country's speed of integration predicts future country's risk-adjusted growth opportunities, while improved risk-adjusted growth opportunities predict future advances in integration, indicating that the countries whose integration has been faster may have benefited most from a virtuous dynamics in which financial integration and improved real prospects are mutually reinforcing. Third, financial integration predicts globalization but the reverse does not necessarily hold, while advances in financial integration predict advances in financial development and improvements in the liquidity of equity markets.
\end{abstract}

JEL Classification Numbers:F36, G15

Keywords: financial integration, growth opportunities, globalization, openness, financial development, liquidity

Author's E-Mail Address:gdenicolo@imf.org; iivaschenko@,imf.org 
Contents

Page

I. Introduction

II. Financial Integration as Convergence in Equity Premia ............................................ 5

III. Risk-Adjusted Growth Opportunities and Financial Integration ............................... 7

IV. Globalization, Financial Development and Liquidity .......................................... 11

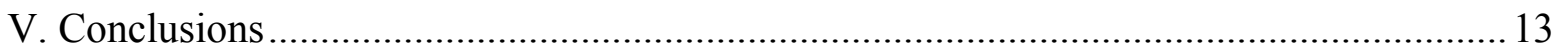

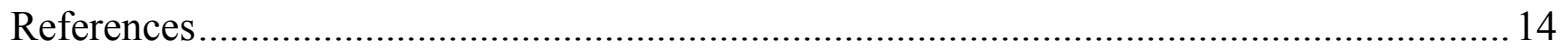

Tables

1. Convergence of Cross-Country Variances of Equity Premia ................................ 16

2. Financial Integration and Risk-Adjusted Growth Opportunities ............................ 17

3. Financial Integration and Globalization...................................................... 18

4. Financial Integration and Financial Development ........................................... 19

5. Financial Integration and Equity Markets Liquidity ........................................ 20

Figures

1. Risk-Adjusted Growth Opportunities - Developed Europe .................................. 21

2. $\quad$ Risk-Adjusted Growth Opportunities - Emerging Europe .................................. 22

3. Risk-Adjusted Growth Opportunities - Americas ...........................................2 23

4. $\quad$ Risk-Adjusted Growth Opportunities - Emerging Asia .......................................24 


\section{INTRODUCTION}

Assessing whether financial integration produces the beneficial real effects resulting from a more efficient resource allocation predicted by theory, and identifying some of the channels through which these benefits are realized, is perhaps what ultimately matters most for people and public policy. This paper analyzes the implications of worldwide and regional financial integration for the efficiency of capital allocation, a relationship that few studies have explored before. ${ }^{1}$

Theory predicts that in a perfectly financially integrated region, capital should be invested where it is expected to earn the highest expected risk-adjusted return. The cost of equity capital within the region should be equalized, as firms and investors would face the same investment opportunities and the same pricing of risk. Therefore, in an imperfectly integrated region experiencing advances in financial integration, one should observe convergence in the cost of equity capital across countries. Furthermore, the degree of convergence in the cost of capital of each country should also have a positive impact on a country's risk-adjusted growth opportunities owing to a more efficient allocation of capital within firms and sectors brought about by integration. This paper evaluates these predictions in the following way.

First, we document advances in measures of financial integration for major developed and emerging markets economies. ${ }^{2}$ As in Bekaert, Harvey and Lundblad (2007) (BHL henceforth), we focus on equity markets, since these markets are either ones in which claims on a "representative" variety of countries' investment opportunities are traded, or represent firms of the most important sectors in an economy. In either case, we may expect a high correlation between risk-adjusted growth opportunities of publicly quoted firms and those of the economy as a whole. Using equity market data also allows us to construct measures that are highly correlated with firms' cost of capital. Specifically, following Adjaouté and Danthine (2004), advances in financial integration are assessed by testing cross-country convergence of equity premia, as equity premia are fundamental determinants of the cost of equity capital firms face.

\footnotetext{
${ }^{1}$ Recent work by Bekaert, Harvey and Lundblad $(2005,2007)$ has focused on the growth effects of integration globally, but not on integration within regions. Adjaouté and Danthine (2004) have assessed financial integration within developed European countries, but have not examined the implications of integration for growth. We are unaware of any study that has examined the potential direct impact of financial integration on other determinants of countries' growth prospects.

${ }^{2}$ Several recent studies have focused on European financial integration, documenting increased convergence in prices of money and bond markets (Barros and others, 2005; Baele and others, 2004; and Adam and others, 2002) in subsets of Euro area countries , and convergence of pricing in equity markets (Adjaouté and Danthine, 2004, De Nicolò and Tiemann, 2006) in sets of Western European economies. Few studies have focused on Emerging Europe countries either considered individually or as a group. This study also contributes to this literature by presenting evidence on a large set of Western European and Emerging Europe economies.
} 
Second, to examine the real effects of financial integration, we construct a measure of riskadjusted growth opportunities for each country, document its evolution, and test whether a measure of the speed of integration, given by the distance of a country's equity premium from the group average, predicts country's risk-adjusted growth opportunities. This test essentially aims at establishing whether a country that experiences increased integration in the form of a reduction in the distance of its equity premium from the group average also witnesses a subsequent increase in its risk-adjusted growth opportunities. The finding of a negative relationship between the country-specific measure of speed of integration and future risk-adjusted growth opportunities would thus suggest that such opportunities indeed improve with the speed of integration. In addition, we also assess the converse, that is, whether improvements in risk-adjusted growth opportunities predict advances in financial integration in the form of a future reduction in the distance measure defined above. This test essentially sheds light on the extent to which advances in financial integration are fostered by better risk-adjusted growth opportunities.

Two main results obtain. First, we find strong evidence of a declining trend in the crosscountry dispersion of equity premia worldwide and such declines have been more pronounced in Emerging Markets countries. Moreover, regional integration has proceeded faster in Europe, with Emerging Europe countries playing an important role. Second, measures of the speed of integration indeed predict subsequent increases in country's riskadjusted growth opportunities, while better risk-adjusted growth opportunities predict future advances in integration. These results hold globally as well as with respect to European integration. They suggest that the benefits of a more efficient allocation of capital prompted by financial integration are significant, and that countries whose speed of integration is faster may benefit from a virtuous dynamic pattern in which financial integration and improved real prospects are mutually reinforcing. Europe is the region which appears to have benefited most from this virtuous dynamic pattern.

Third, we examine three potential channels through which financial integration may have a positive impact on countries' growth prospects: globalization as financial openness, financial development and market liquidity. In this regard, we obtain two additional results. First, financial integration measures predict globalization measures, but the reverse does not hold necessarily. This suggests that the beneficial effects of globalization found in the literature (e.g. Bekaert, Harvey and Lundblad, 2005) may be in part driven by an underlying financial integration process. Second, measures of financial integration predict both progress in financial development and improvements in equity markets liquidity, but the converse does not hold. This result suggests a casual relationship from financial integration to financial development and equity market liquidity, with financial development and improved liquidity being the channels through which integration may lead to improvements in countries' growth prospects.

The remainder of the paper consists of four sections. Section II assesses convergence in equity premia. Section III documents the evolution of measures of risk-adjusted growth opportunities, and presents the tests assessing the predictive power of measures of financial integration on risk-adjusted growth opportunities and the converse. Section IV examines the 
predictive power of measures of financial integration for globalization, financial development and equity market liquidity. Section V concludes.

\section{Financial Integration as Convergence in Equity Premia}

Advances in financial integration are gauged by testing whether there is a significant decline in the cross-country dispersion of a proxy measure of equity premia. ${ }^{3}$ As discussed in Adjaouté and Danthine (2004), convergence in equity premia is directly associated with convergence in the cost of capital. Following De Nicolò and Tiemann (2008), a simple statistical model for the dynamics of the cross-country dispersion of equity premia is obtained as follows.

Let $X_{i t}$ denote the equity premium in country $i$ at date $t . X_{i t}$ turns out to be well described by the following autoregressive model:

$$
X_{i t}=\alpha_{i t}+\gamma_{i} X_{i t-1}+\varepsilon_{i t}
$$

As customary, the innovations $\varepsilon_{i t}$ are assumed to be i.i.d.

To obtain a model for the cross-country variance of equity premia, note that the conditional mean of $X_{i t}$ is given by $m_{t-1}\left(X_{i t}\right) \equiv \alpha_{i t}+\gamma_{i} X_{i t-1}$. Assume that the coefficients $\left\{\alpha_{i t}, \gamma_{i}\right\}$ are distributed cross-sectionally with means $\left\{\alpha_{t}, \gamma\right\}$ and variances $\left\{\sigma_{\alpha t}^{2}, \sigma_{\gamma}^{2}\right\}$, and that covariances among all these random variables are approximately nil. Under these assumptions, the cross-sectional variance of $m_{t-1}\left(X_{i t}\right)$ is given by

$$
\sigma_{X}^{2}(t) \equiv E\left(m_{t-1}\left(X_{i t}\right)-E m_{t-1}\left(X_{i t}\right)\right)^{2}=\sigma_{\alpha t}^{2}+\sigma_{\gamma}^{2} \sigma_{X}^{2}(t-1)
$$

Increased convergence in equity premia occurs if $\sigma_{\alpha t}^{2}$ exhibits a declining path. We estimate the following counterpart of model (2) :

$$
\bar{\sigma}_{X}^{2}(t)=A_{0}+A_{1} t+A_{2} \bar{\sigma}_{X}^{2}(t-1)+\eta_{t}
$$

Convergence in the cross-country dispersion of equity premia occurs if $A_{1}$ is negative. We focus on testing this implication of convergence.

\footnotetext{
${ }^{3}$ As shown in Solnik and Roulet (2000), under the assumption that the data generating process of equity premia is described by a factor model, the evolution of their cross-sectional dispersion is inversely related to their pairwise correlation.
} 
Equity premia are ex-ante measures notoriously difficult to estimate using historical data. However, a standard approach is to use ex-post equity excess returns under the assumption that the time average of ex-post and ex-ante excess returns are equal. Thus, we use ex-post equity excess returns as proxy measures of equity premia.

We use monthly equity market data for the period February 1985-May 2007 for 52 countries, including developed countries and emerging market countries in Europe, Asia and America, taken from Datastream and Standard \& Poors. ${ }^{4}$ The risk free rate is the yield on government securities at maturities ranging from one month to three months, depending on data availability.

By estimating equations (3) including all countries, we test world convergence in equity premia. Estimates of equation (3) are also presented for two different types of country subsamples. The first type of subsample excludes from the whole sample countries that belong to a particular region. In this case, a comparison of the estimated coefficient obtained when all countries are included with that obtained by excluding a subsample gauges the relative contribution of that subsample to worldwide equity premia convergence. Specifically, we compare estimates of the trend coefficient $A_{1}$ when $\bar{\sigma}_{X}^{2}(t)$ is computed by including all countries in the sample, with estimates of the trend coefficient when $\bar{\sigma}_{X}^{2}(t)$ is computed excluding all countries in a given subsample. The second type of subsample includes only countries in a particular region. Thus, estimates of the trend coefficient $A_{1}$ provides a gauge of equity premia convergence within a region, that is, a measure of regional financial integration.

Table 1 reports the results. As shown in the estimates obtained including all countries (Equation (1)), the trend coefficient is negative and significant, indicating strong world convergence in equity premia. As shown in Equation (2), world convergence is importantly driven by convergence in Emerging Markets countries, as the trend coefficient is lower in absolute value than that obtained when all countries are included.

Looking at the contribution of regions to world convergence, we find that Asian countries, when treated as a block, do not contribute significantly to world convergence, since the trend coefficient in Equation (3) is larger in absolute value than that in Equation (1). This result indicates that financial integration of countries in the Asian region is proceeding at a different

\footnotetext{
${ }^{4}$ Each regional sample includes developed and emerging countries. Developed America includes the United States and Canada. Emerging America includes the following 6 countries: Mexico, Argentina, Brazil, Chile, Colombia and Peru. Developed Asia includes Hong Kong, Korea, Singapore, Japan, Australia and New Zeland. Emerging Asia includes the following 8 countries: China, India, Indonesia, Malaysia, Pakistan, Philippines, Taiwan Rep of China, Thailand. Developed Europe includes the following 16 countries: Austria, Belgium, Denmark, Finland, France, Germany, Greece, Ireland, Italy, Netherlands, Norway, Portugal, Spain, Sweden, Switzerland and the United Kingdom. Emerging Europe includes the following 13 countries: Czech Republic, Hungary, Poland, Rumania, Russia, Bulgaria, Croatia, Estonia, Latvia, Lithuania, Slovakia, Slovenia and Ukraine.
} 
pace and intensity. In other words, there exists heterogeneity of the financial integration process among the countries in Asia. By contrast, the Latin American and European regions have contributed significantly to world integration, as witnessed by an absolute value of the trend coefficients in the relevant equations (Equations (4) and (5)) lower than that in Equation (1). Importantly, the drop of the trend coefficient in these estimates relative to the world estimate is largest for Europe. This indicates that European financial integration has proceeded at the fastest pace.

The above results are consistent with the following findings concerning regional integration. Estimates for the Asia region yield a trend coefficient not significantly differing from zero (Equation (6)), again indicating heterogeneity in the financial integration process among these countries. The results for Latin America and Europe are strikingly different: these exhibit strong regional financial integration (Equations (7) and (8)), as the trend coefficient in the relevant equations is negative and significant. With regard to European financial integration, the estimates of the trend coefficient obtained with Equation (8) is significantly larger, in absolute value, than that estimated when Emerging Europe countries are excluded (Equation (9)). Thus, countries in Emerging Europe have experienced a convergence faster than the group of other countries, thereby significantly contributing to convergence within the region.

In sum, world financial integration as convergence in equity premia has progressed significantly. It has been primarily driven by advances in Emerging Markets countries, and by countries in Latin America and Europe. European integration has progressed faster than in the other regions, driven by the fast pace of integration of Emerging Europe countries. These results are also consistent with those obtained by recent work by Garcia-Herrero and Wooldridge (2007), who find evidence of a decreasing correlation between domestic investment and savings, which is an implication of increased financial integration.

\section{RISK-ADJUSTED GROWTH OPPORTUNITIES AND FINANCIAL INTEGRATION}

A standard forward-looking measure of growth opportunities is given by the evolution of the price-to-earnings ratio. Similarly to BHL, we assess progress in financial integration by constructing country measures of growth opportunities based on measures of total equity market price-to-earnings ratios. These measures are equivalent to earnings-weighted averages of firms' price-to-earnings ratios. Furthermore, we adjust these measures for risk, since price-to-earnings ratios exhibit significant fluctuations, reflecting both market uncertainty regarding future growth of the economy as well as the temporary appearance of "bubble" components in some equity market prices. This risk adjustment is especially important, since what is likely to improve economies' well-being is risk-adjusted growth. In other words, expected welfare is likely to be lower in an economy with very high, but very uncertain, growth prospects compared to another economy where the overall (growth) riskreturn trade-off is relatively more favorable. 
To account for cross-country differences in industry composition of each country's price-toearnings ratio, we standardize these ratios by the world price-to-earnings ratio. As discussed in BHL, doing this is akin to evaluate country growth opportunities relative to a proxy measure of global growth opportunities. Thus, our measure of risk-adjusted growth opportunities for country $\mathrm{j}$ in month $\mathrm{t}$, called $R A G O$, is given by:

$$
R A G O_{j t}=\frac{P E_{j t} / P E_{w t}}{\sigma_{j t}}
$$

where $P E_{j t}$ denotes the country j's total market price-to-earnings ratio, $P E_{w t}$ is the world price-to-earnings ratio, and $\sigma_{j t}$ is a rolling standard deviation of the ratio $P E_{j t} / P E_{w t}$ computed in each month using data of the preceding twelve months. ${ }^{5}$

Figures 1-5 depict the evolution of $R A G O$ for all countries for which this measure could be constructed since January 1994. Notably, all European countries exhibit a non-declining trend with the only exception of Norway, and the trend is significantly upward in many countries, especially in Emerging Europe. In America, $R A G O$ is upward sloping in the U.S., Mexico, Brazil and Chile, while declines in the other countries of the group. In Asia, an upward trend in $R A G O$ is exhibited by China, India, Pakistan, Hong Kong, Korea and Singapore. Interestingly, in all regions a combination of developed and emerging market economies exhibit an upward trend in $R A G O$. Remarkably, most countries in Europe exhibit such an upward trend.

Next, we address the following key questions. Does a country's speed of integration have a positive impact on future risk adjusted opportunities? The finding of a positive impact would suggest that financial integration has indeed expected real effects. Conversely, do improvements in risk adjusted opportunities have a positive impact on the future speed of integration? In this case, the finding of a positive impact would suggest that improvements in growth prospects may spur subsequent financial integration.

To address these questions, we first construct simple measures of speed of integration within a given set of countries. A simple proxy measure of speed of integration is given by a measure of the distance of the equity premium of a country from a measure of central tendency of the cross-country distribution of equity premia in the entire sample considered. Specifically, for country $\mathrm{j}$ in year $\mathrm{t}$ this measure, called ISPEED, is given by :

$$
\operatorname{ISPEED}_{j t}=\left(X_{j t}-\hat{X}_{t}\right)^{2}
$$

\footnotetext{
${ }^{5}$ A similar Sharpe ratio-type measure can be obtained by positing a one-factor model for the price-to-earnings ratio of each country with the world price-to-earnings ratio as a factor. All results presented below remain essentially the same with the standard deviation computed over a 24 month horizon.
} 
where $X_{j t}$ is the equity premium and $\hat{X}_{t}$ is the mean of the distribution of equity premia across the countries considered. This measure records the position of the equity premium of a country relative to the group within the cross country distribution. The faster is financial integration in a country, the smaller the (quadratic) distance of its equity premium from the group central tendency. Note that a desirable feature of this measure is that it accounts for time variation of both the equity premium of a country and the average of the group it belongs to.

Second, the dynamics of $R A G O$ and ISPEED are modeled as simple autoregressive processes conditioned on their own past values in a VAR-type fashion. The coefficient associated with past values of the speed of integration in the $R A G O$ equation yields an estimate of the impact of this speed on future country's risk-adjusted growth opportunities, while the coefficient associated with past values of $R A G O$ in the equation of integration speed yields an estimate of the impact of $R A G O$ on future integration speed. Thus, the impact of the speed of integration (risk-adjusted growth opportunities) on future riskadjusted growth opportunities (future speed of integration) is assessed by positing the following statistical panel data models for $R A G O$ and ISPEED:

$$
\begin{gathered}
R A G O_{j t}=\alpha_{1 j}+\beta_{1} I_{\text {SPEED }} \text { PIt-1 }_{1}+\gamma_{1} R A G O_{j t-1}+\delta Y_{1 t-1}+\varepsilon_{1 j t} \\
\operatorname{ISPEED}_{j t}=\alpha_{2 j}+\beta_{2} R A G O_{j t-1}+\gamma_{2} I S P E E D_{j t-1}+\delta Y_{2 t-1}+\varepsilon_{2 j t}
\end{gathered}
$$

In both equations, $\alpha_{1 j}$ and $\alpha_{2 j}$ are country-specific effects and $Y_{i t-1}, \mathrm{i}=1,2$, is a vector of time-specific controls to be defined momentarily. The main objective is to estimate the coefficients $\beta_{1}$ and $\beta_{2}$, and test whether their values are negative and significantly different from zero.

One important issue to confront is the possible presence of unit roots in the (panel) data generating process for $R A G O$ and ISPEED, since these measures exhibit high persistence. This could make it difficult to carry out valid inference on the coefficients of interest should the unit root hypothesis fail to be rejected. We address this problem by adopting a specification of (6) and (7) along the lines suggested by Pesaran (2007), which makes it feasible to test both whether the unit root hypothesis can be rejected and whether the coefficients $\beta_{1}$ and $\beta_{2}$ are negative and significant.

Subtracting the lagged value of the dependent variable from (6) and (7), setting the vector of time specific controls equal to the cross-sectional average of lagged level and first difference of the dependent variable, and denoting with $\Delta$ first differences, we estimate the following two equations:

$$
\triangle R A G O_{j t}=\alpha_{1 j}+\beta_{1} I S P E E D_{j t-1}+\left(\gamma_{1}-1\right) R A G O_{j t-1}+\delta_{11} A R A G O_{t-1}+\delta_{12} A \Delta R A G O_{t-1}+\varepsilon_{1 j t}
$$




$$
\begin{aligned}
& \triangle I S P E E D_{j t}=\alpha_{2 j}+\beta_{2} R A G O_{j t-1}+\left(\gamma_{2}-1\right) \operatorname{ISPEED}_{j t-1}+\delta_{12} \text { AISPEED }_{j t-1}+ \\
& +\delta_{22} A \triangle I S P E E D_{j t-1}+\varepsilon_{2 j t}
\end{aligned}
$$

In equation (8), $A R A G O_{t-1}=N^{-1} \sum_{j=1}^{N} R A G O_{j t-1}$ and $A \Delta R A G O_{t-1}=N^{-1} \sum_{j=1}^{N} \Delta R A G O_{j t-1}$ are the cross-sectional averages of lagged values of $R A G O$ and its first difference respectively. In equation (9), AISPEED $D_{t-1}=N^{-1} \sum_{j=1}^{N} I_{S P E E D_{j t-1}}$ and $A \triangle I S P E E D_{t-1}=N^{-1} \sum_{j=1}^{N} \triangle I S P E E D_{j t-1}$ are the cross-sectional averages of lagged values of ISPEED and its first difference respectively. The (panel) unit root hypothesis is rejected if $\gamma_{i}-1<0, \mathrm{i}=1,2$.

Table 2 reports the results of these fixed effects specification for the entire sample and for Europe, Asia and Latin America. ${ }^{6}$ First note that in all estimates, the unit roots hypothesis is rejected with high confidence, since the robust t-statistics associated with $\gamma_{i}-1<0, \mathrm{i}=1,2$ are well below the cross-sectionally augmented Dickey-Fuller critical values obtained in Pesaran (2007) at 1 percent confidence levels.

In the world sample (Equation (1)), both the coefficients $\beta_{1}$ and $\beta_{2}$ are negative and significant at conventional significance levels. This finding suggest the existence of a virtuous dynamics, whereby a more efficient allocation of capital spurred by financial integration improves future risk-adjusted growth opportunities and, in turn, improved riskadjusted growth opportunities speed up financial integration.

When we look at the same relationships in the context of regional integration, as opposed to world integration, we obtain results consistent with the convergence results in equity premia described previously. The European sample exhibits the same pattern of the world sample: both the coefficients $\beta_{1}$ and $\beta_{2}$ are negative and significant (Equation (2)), indicating that the virtuous dynamics between financial integration and risk adjusted growth opportunities holds at regional level as well. By contrast, such dynamics does not show up in the data for the Asian sample (Equation (3)), confirming the degree of heterogeneity of the Asian countries in their financial integration process. Lastly, in the Latin American sample both the coefficients $\beta_{1}$ and $\beta_{2}$ are negative (Equation (4)), but only the coefficient $\beta_{2}$ is significant, indicating that the positive impact of improved growth opportunities on financial integration dominates the reverse impact.

\footnotetext{
${ }^{6}$ For the world and all regions, the same results (even statistically stronger) obtain when estimates of (8) and (9) are carried out assuming a random effects model.
} 
In sum, a country-specific measure of integration predicts a measure of a country's riskadjusted growth opportunities. Thus, increased financial integration has overall improved the efficiency of capital allocation worldwide, and particularly that of countries that are integrating most rapidly.. Regional financial integration appears to have played a significant growth-enhancing role in Europe. Conversely, better risk-adjusted growth opportunities foster future advances in integration. These results suggest that the world, and particularly Europe, has witnessed a virtuous dynamics in the past decade: increased financial integration has improved the efficiency of capital allocation, and countries that have improved their riskadjusted growth opportunities have witnessed an acceleration of their financial integration.

\section{GLOBALIZATION, FinANCIAL DEVELOPMENT AND LIQUIDITY}

In the previous section, we illustrated a direct positive effect of financial integration on growth prospects. This section examines some specific channels through which financial integration is likely to improve countries' growth prospects. Although a full identification of these channels is outside the scope of this paper, here we focus on three potential channels: financial globalization, financial developments and market liquidity.

\section{Financial Integration and Globalization}

Recent empirical work found the relationship between globalization (defined as financial openness) and growth to be positive but rather weak (IMF, 2007). Nevertheless, we analyze the nexus between integration and globalization because some empirical research has equated financial integration with measures of financial globalization (or openness). For example, Kose, Prasad, Rogoff and Wei (2006) assert that measures based on capital flows "provide the best available measure of a country integration with international financial markets" (p.9). Yet, financial integration and globalization (openness) are different concepts.

In a broad sense, financial markets are integrated if the law of one price applies to any traded financial assets with similar characteristics. In the context of any standard general equilibrium model with financial assets, financial integration means equality of the expected discount factor used to price financial assets. In turn, a common expected discount factor equates investors' intertemporal marginal rates of substitutions. Hence, while globalization is necessary for international financial integration to occur, it may be not sufficient to guarantee that a country's financial system is integrated with world markets in ways that foster an efficient capital allocation. For example, Stultz (2005) has stressed how poor corporate governance can be an impediment to financial integration.

To assess the extent to which these arguments are borne out by the data, we followed IMF (2007) by taking the sum of external assets and liabilities relative to GDP as our measure of financial globalization-where the numerator is taken from the database constructed by Lane and Milesi-Ferretti (2007) - and ISPEED as our measure of financial integration. Then, we estimated two dynamic panel models relating lagged values of the annual growth rate of globalization and our measure of financial integration to assess whether financial integration 
predicts advances in globalization, and whether the reverse also holds. Estimations in this sub-section and the following one were conducted using GMM. ${ }^{7}$ Estimations are done at a yearly frequency, as dictated by Lane and Milesi-Ferretti (2007) dataset.

As shown in Table 3, an advance in financial integration (a reduction in ISPEED) predicts an advance in globalization (an increase in the growth rate of globalization). This is true for the entire sample, for the sub-sample that includes only emerging markets, as well as at a regional level and within regions. Conversely, financial globalization predicts integration, but not in all cases. The important exception is the Asian region (equations (3) and (5) in Table 3 ). These results suggest the existence of a casual relationship from financial integration to globalization, indicating that globalization has been a necessary but not sufficient condition for financial integration in Asia. Hence, financial integration appears to be a driver of globalization, but globalization does not necessarily imply integration, which may explain the weak predictive power of globalization (measured as openness) for growth.

\section{Financial Integration and Development}

A large literature has established the important role that financial development plays in ensuring growth (Levine, 2005). A widely used measure of financial deepening at a country level is the ratio of total private credit supplied by the banking system relative to GDP. Tacking the growth rate of this measure for our sample, we assessed whether financial integration predicts financial development using a two equations dynamic model similar to the one used previously.

As shown in Table 4, an advance in financial integration predicts an advance in financial development. As before, this predictive relationship holds for the entire sample, as well as for sample breakdowns by regions and within regions. By contrast, in all cases financial development does not predict integration, suggesting the existence of a casual relationship from financial integration to financial development.

This novel result is important for two reasons. First, it suggests that integration of a key financial market such as the equity market can be instrumental in spurring progress in the entire financial system, and particularly in the banking sector, since our measure of financial development is essentially bank-based. Second, it supports our initial claim - and the focus on equity market integration of part of the literature - that equity market integration is a key indicator of financial integration more generally, since it involves a market in which claims to future real activity are traded and valued: progress in valuation in this market can signal improvements in asset valuations of the corporate and household sectors more generally, all factors likely fostering financial development.

\footnotetext{
${ }^{7}$ We also estimated all models including time fixed effects. The results are essentially the same.
} 


\section{Financial Integration and Liquidity}

Lastly, improved liquidity in equity markets is a necessary condition for asset valuations to readily reflect changes in fundamentals, as well as being instrumental in lowering firms' cost of capital. We assessed whether our measure of financial integration predicts advances in equity market liquidity, as measured by the value of the stock market turnover.

As shown in Table 5, an advance in financial integration predicts an advance in equity markets liquidity. As before, this predictive relationship holds for the entire sample, as well as for sample breakdowns across and within regions with the exception of the Asian region. Thus, a further indirect benefit of financial integration lies in its fostering equity market liquidity.

Summing up, simple tests indicate that financial integration predicts advances in globalization, while globalization does not necessarily predicts advances in integration. In addition, the results suggest that financial integration fosters both financial development and improvements in equity markets liquidity, potentially important determinants of economic growth.

\section{Conclusions}

This paper has analyzed the implications of worldwide and regional financial integration for the efficiency of capital allocation, reaching three main conclusions. First, financial integration has progressed significantly worldwide, and particularly in emerging markets and within Europe. Second, measures of the speed of integration predict subsequent increases in country's risk-adjusted growth opportunities, while better risk-adjusted growth opportunities predict future advances in integration. Third, financial integration predicts advances in globalization but not necessarily the reverse. In addition, financial integration fosters both financial development and improvements in equity markets liquidity.

These results suggest that financial integration is likely to yield the beneficial real effects resulting from a more efficient resource allocation predicted by theory. Policies aimed at opening up capital markets and financial sectors are necessary, albeit not sufficient, to allow countries to reap these benefits. 


\section{References}

Adam, Klause, Tullio Jappelli, Annamaria Menichini, Mario Padula, and Marco Pagano (2002), "Analyze, Compare and Apply Alternative Indicators and Monitoring Methodologies to Measure the Evolution of Capital Market Integration in the European Union", Report to the European Commission (Brussels: European Commission).

Adjaouté, Kpate, and Jean-Pierre Danthine, 2004, "Equity Returns and Integration: Is Europe Changing?" Oxford Review of Economic Policy, 20, 4, 555-70.

Baele, Lieven, Annalisa Ferrando, Peter Hördahl, Elizaveta Krylova, and Cyril Monnet, 2004, "Measuring Financial Integration in the Euro Area," Oxford Review of Economic Policy, 20, 4, 509-530.

Barros, Pedro Pita, Erik Berglöf, Paolo Fulghieri, Jordi Gual, Colin Mayer, and Xavier Vives, 2005, "Integration of European Banking: The Way Forward," CEPR, MED 2.

Bekaert, Geert, Campbell Harvey, and Christian Lundblad, 2005, "Does Financial Liberalization Spur Growth?”, Journal of Financial Economics, 77, 3-55.

Bekaert, Geert, Campbell Harvey, and Christian Lundblad, 2007, “Global Growth Opportunities and Market Integration”, Journal of Finance, 62(3), 1081-1137.

De Nicolò, Gianni, Alexander Tieman, 2008, "Economic Integration and Financial Stability: A European Perspective", Chapter 12 in Building the Financial Foundations of the Euro - Experiences and Challenges, Editors: Lars Jonung, Christoph Walkner and Max Watson, Rutledge, London.

Garcia-Herrero, Alicia and Philip Wooldridge, 2007, "Global and Regional Financial Integration: Progress in Emerging Markets", BIS Quarterly Review, September, 5770 .

IMF, 2007, "Reaping the Benefits of Financial Globalization”, Discussion Paper, http://www.imf.org/external/np/res/docs/2007/0607.htm.

Kose, Ayhan, Eswar Prasad, Kenneth Rogoff, and Shang-Jin Wei, 2006, "Financial Globalization: A Reappraisal”, NBER Working Paper \# 12484.

Lane, Philip R. and Gian Maria Milesi-Ferretti, 2007, "The External Wealth of Nations mark II: Revised and Extended Estimates of Foreign Assets and Liabilities", Journal of International Economics, Vol. 73, Issue 2, 223-250. 
Levine, Ross, 2005, "Finance and Growth: Theory and Evidence", in Handbook of Economic Growth, Philippe Aghion and Steven Durlauf, eds., Amsterdam, The Netherlands: Elsevier Science, 865-934.

Pesaran, Hashem, 2007, “A Simple Panel Unit Root Test in the Presence of Cross Section Dependence" Journal of Applied Econometrics, Vol.22, 265-312..

Solnik, Bruno, and Jacques Roulet, 2000, "Dispersion as Cross-Sectional Correlation" Financial Analyst Journal, 56, 1, 54-61.

Stulz, René M., 2005, “The Limits of Financial Globalization”, Journal of Finance, Vol. LX, no.4, 1595-1638. 


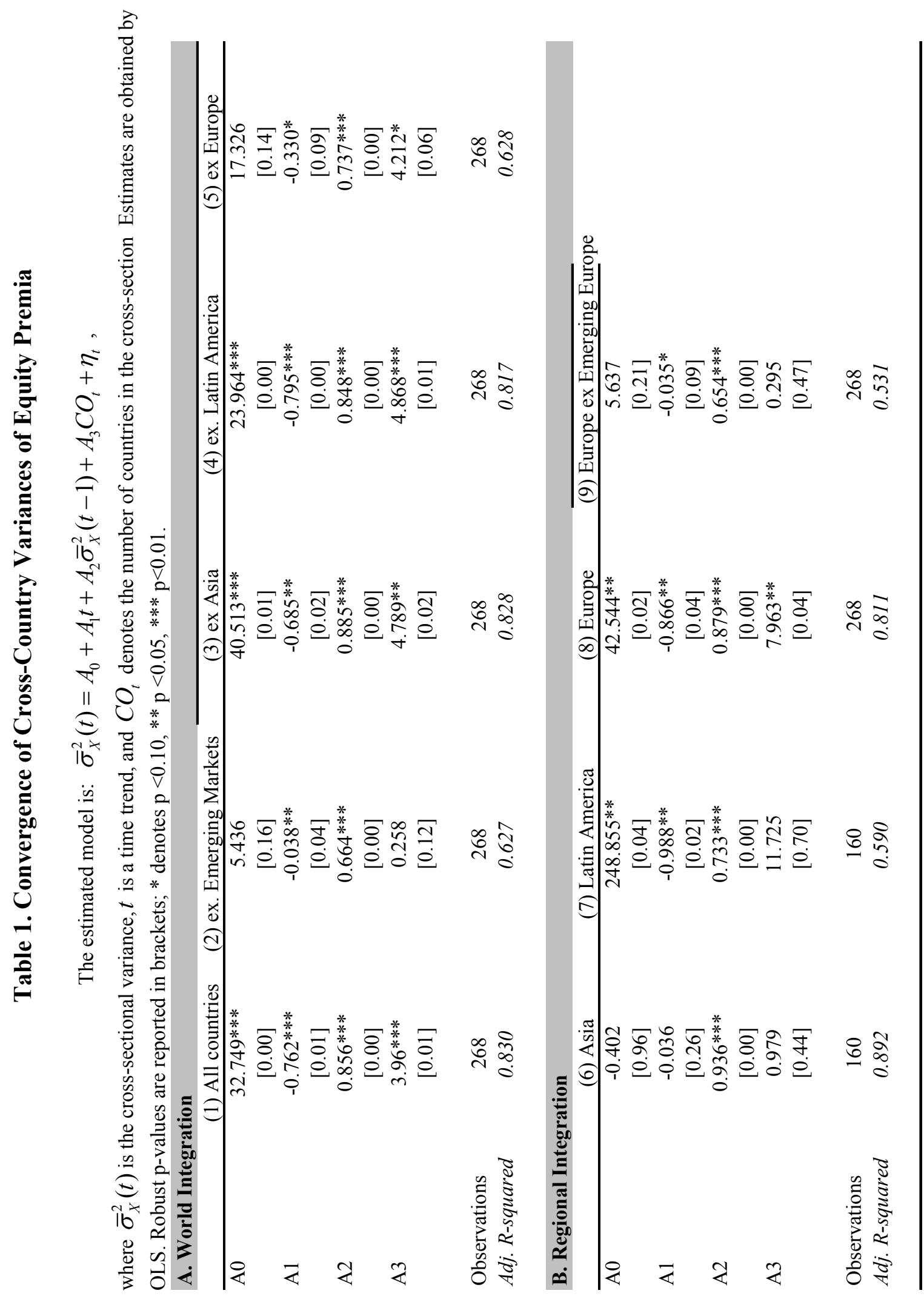




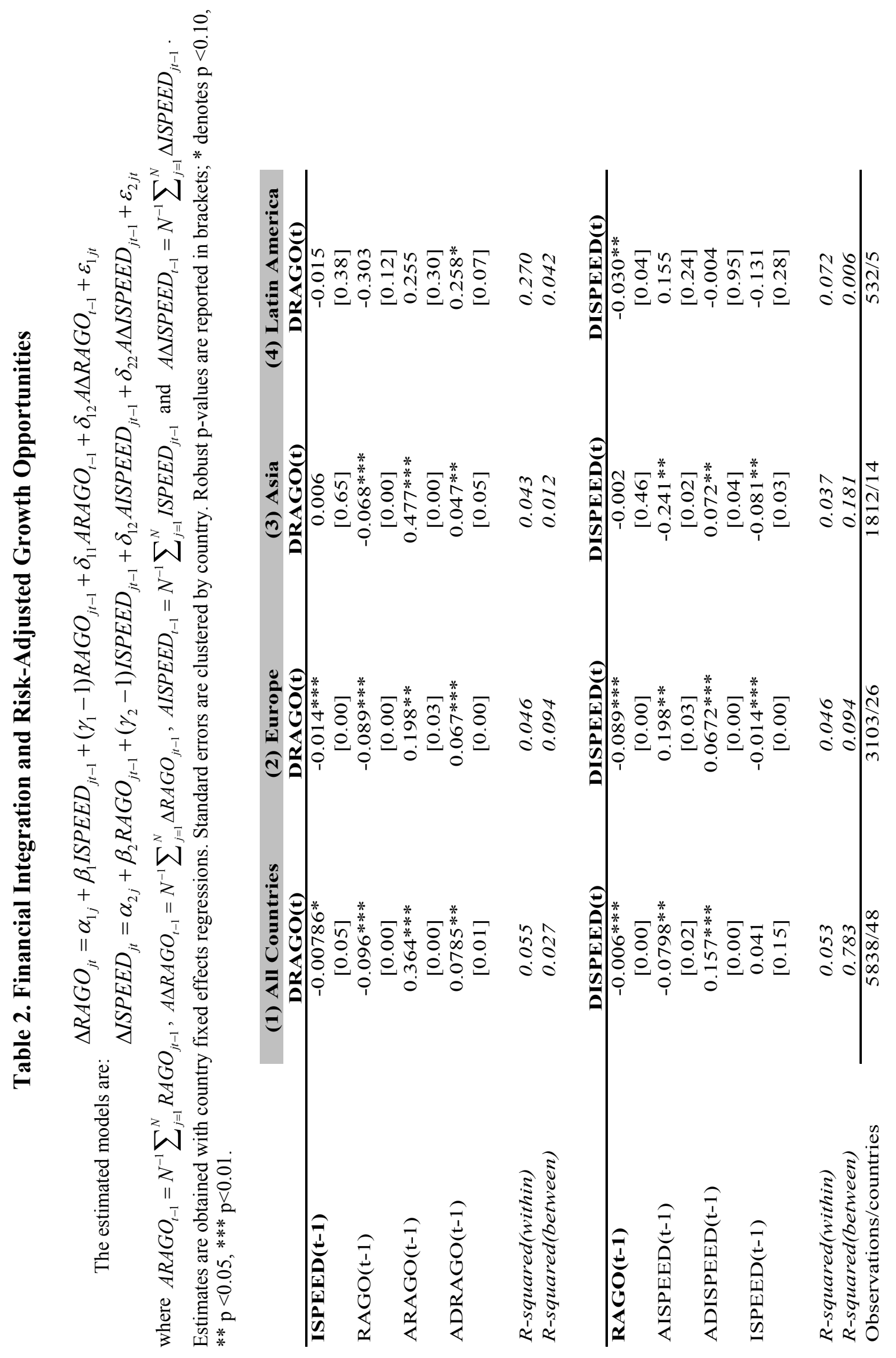




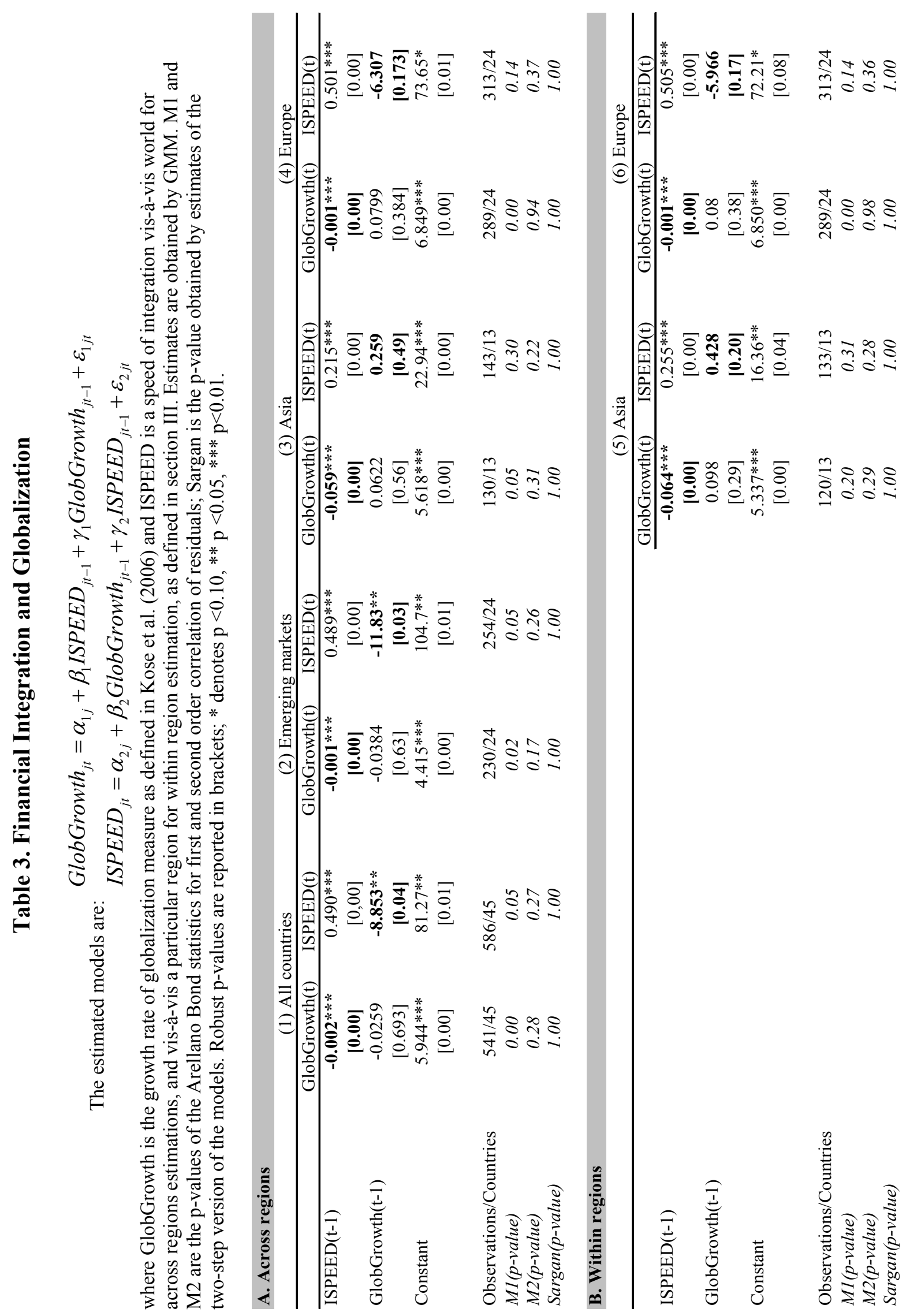




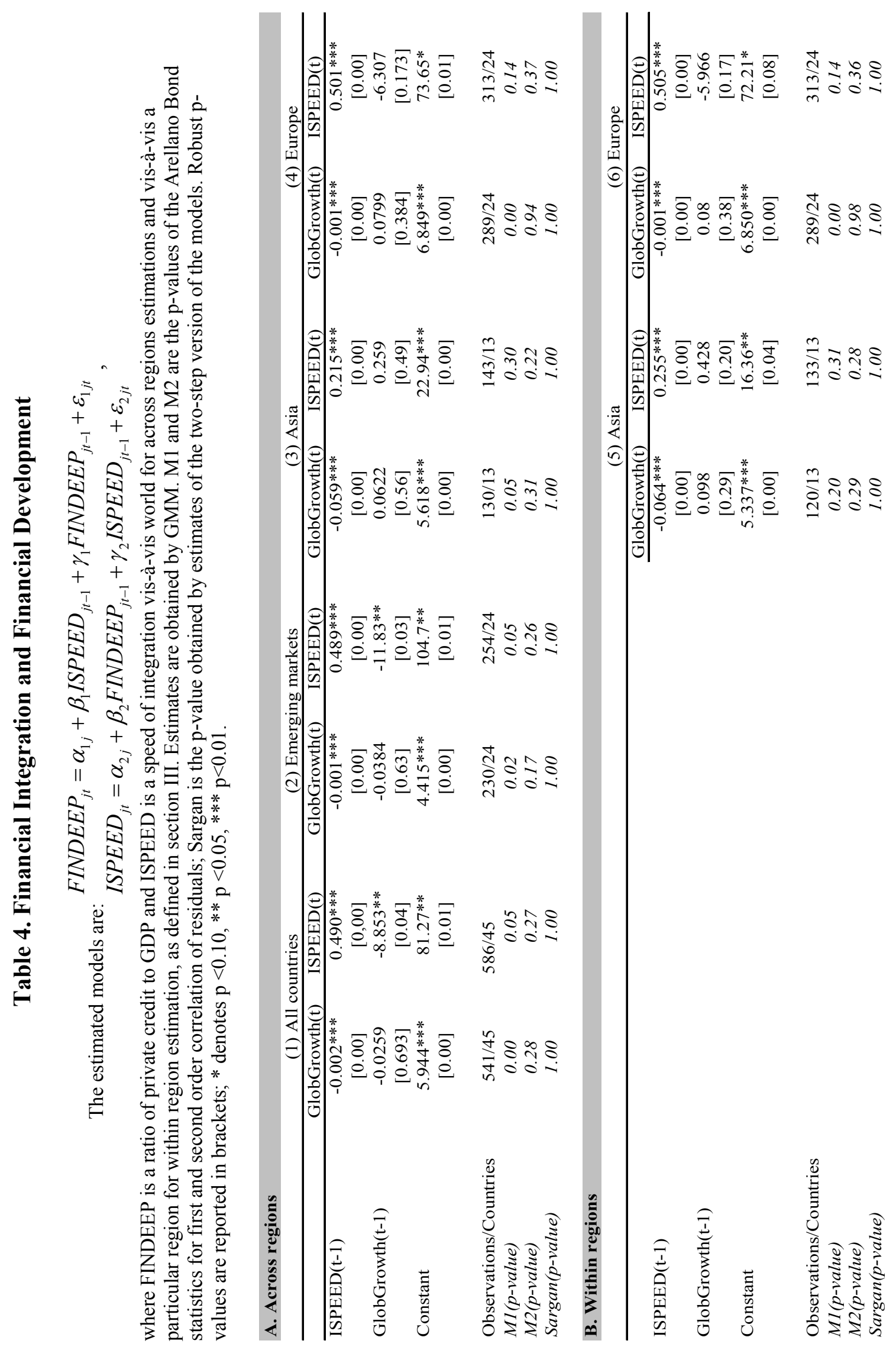




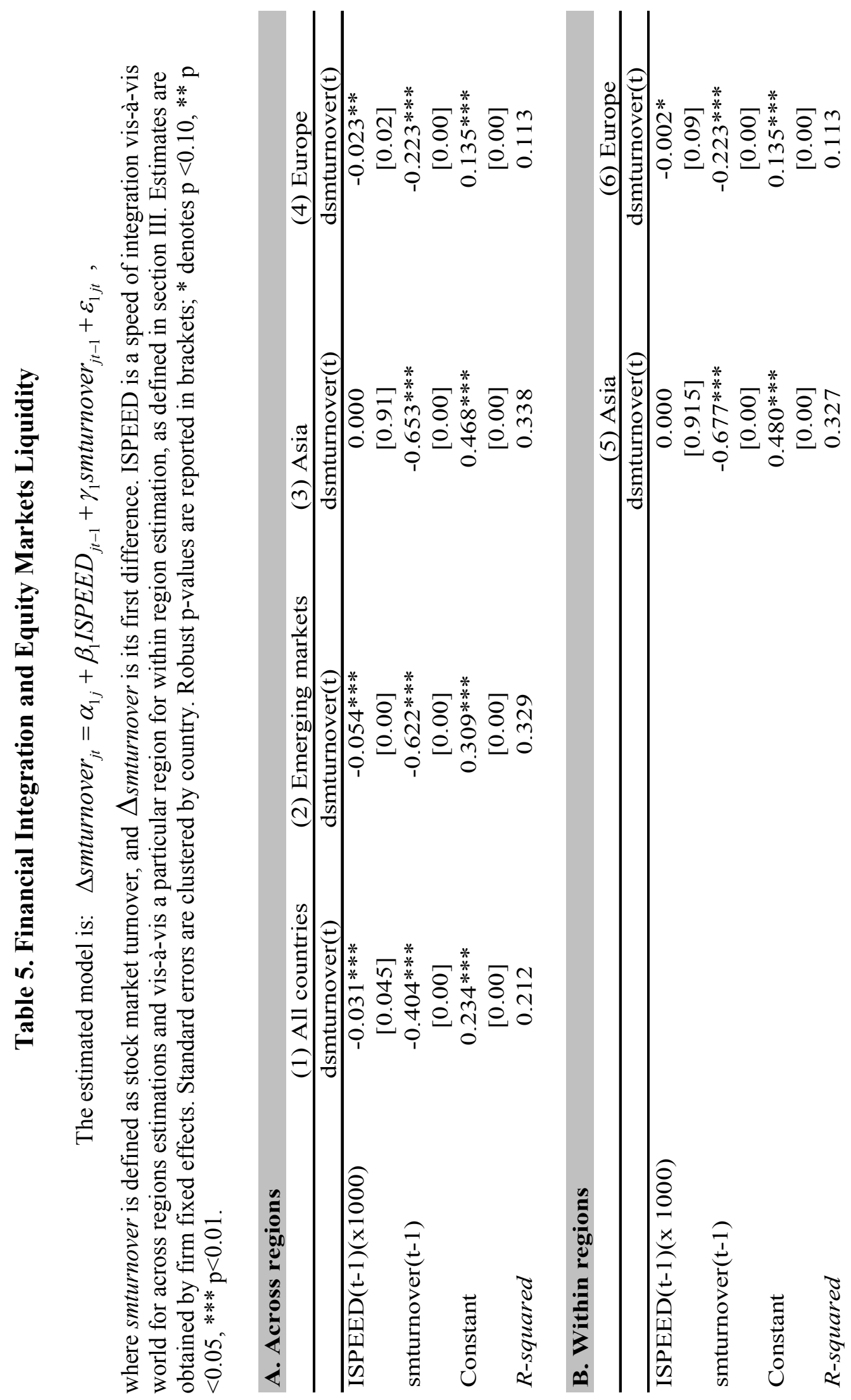




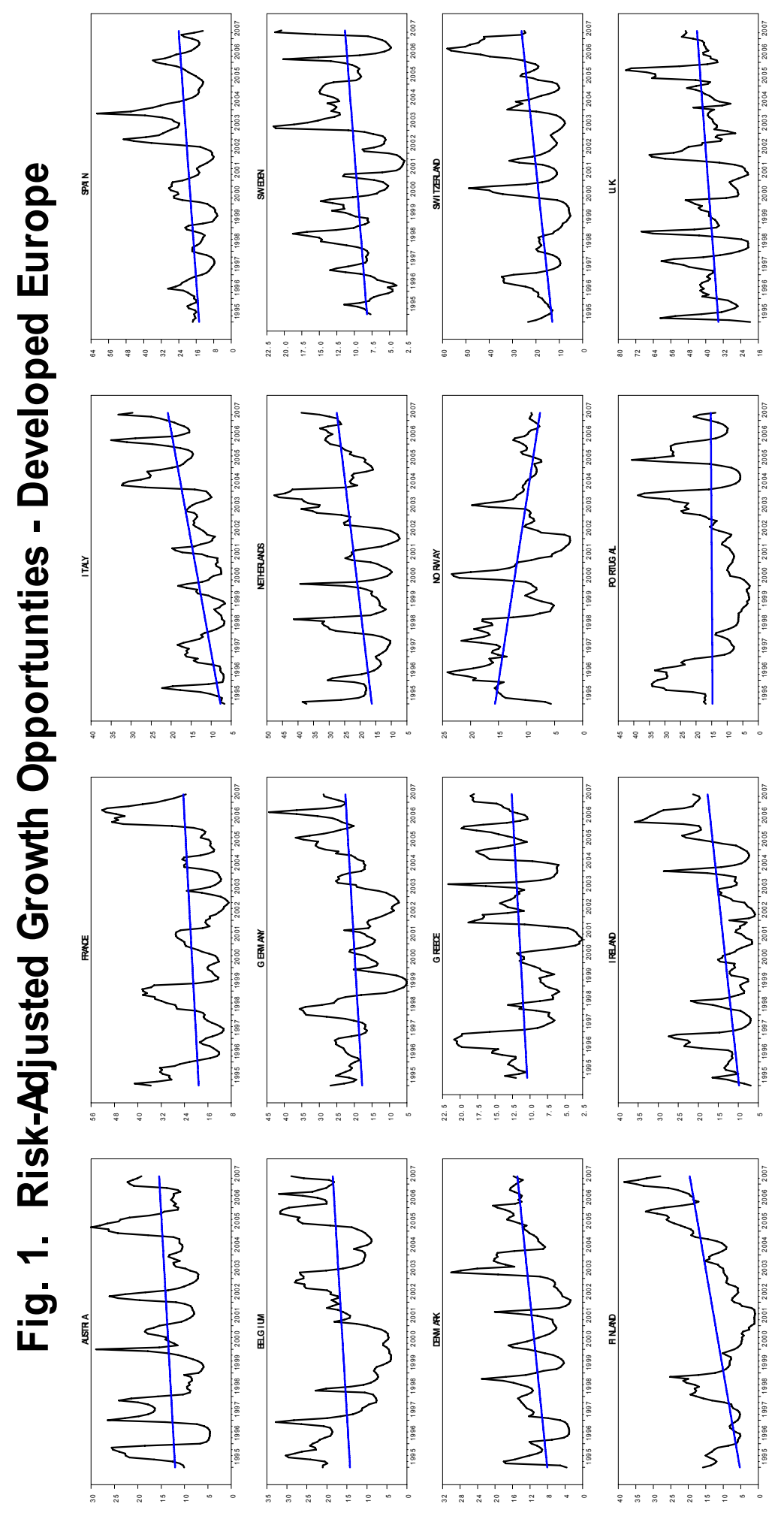




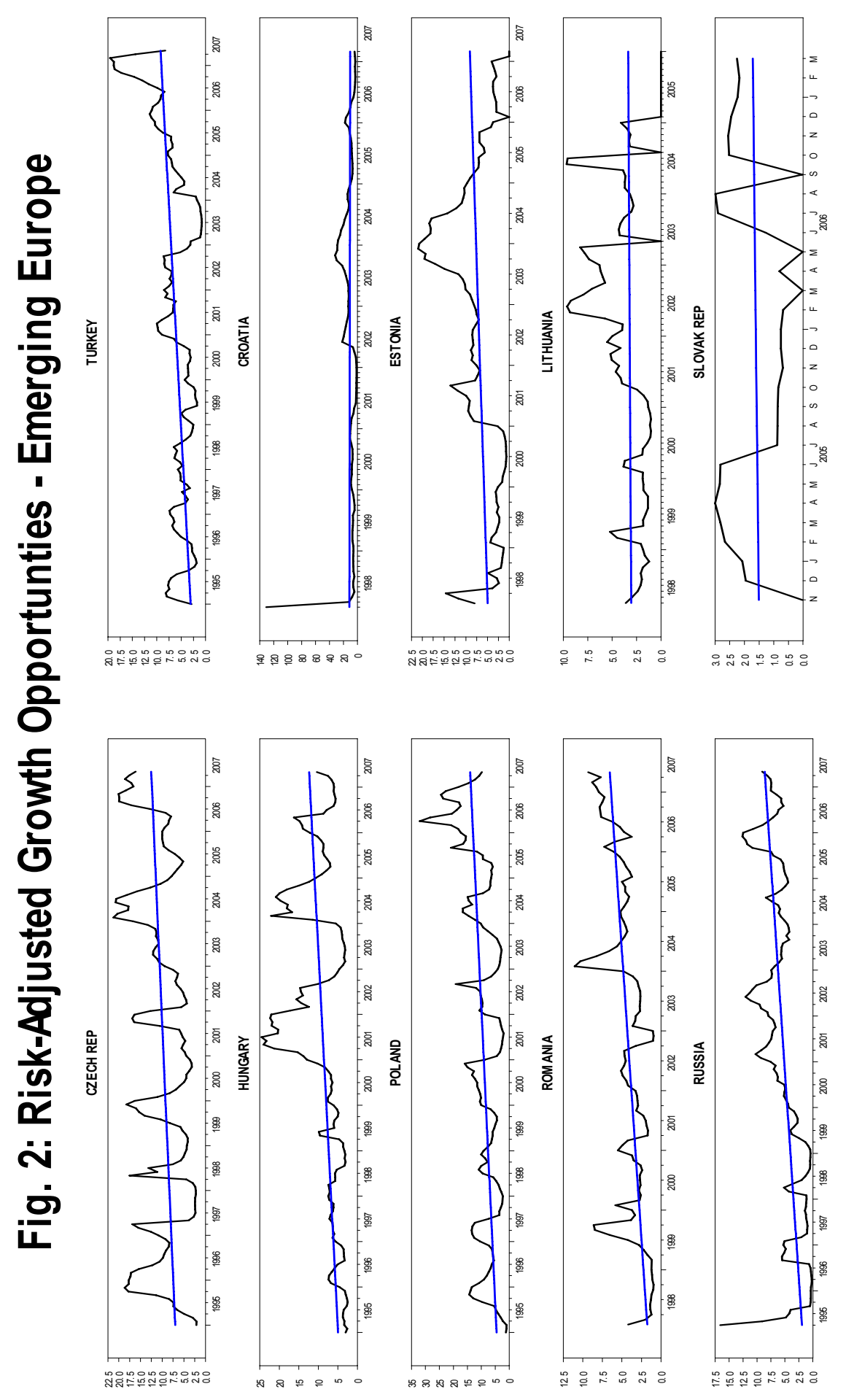




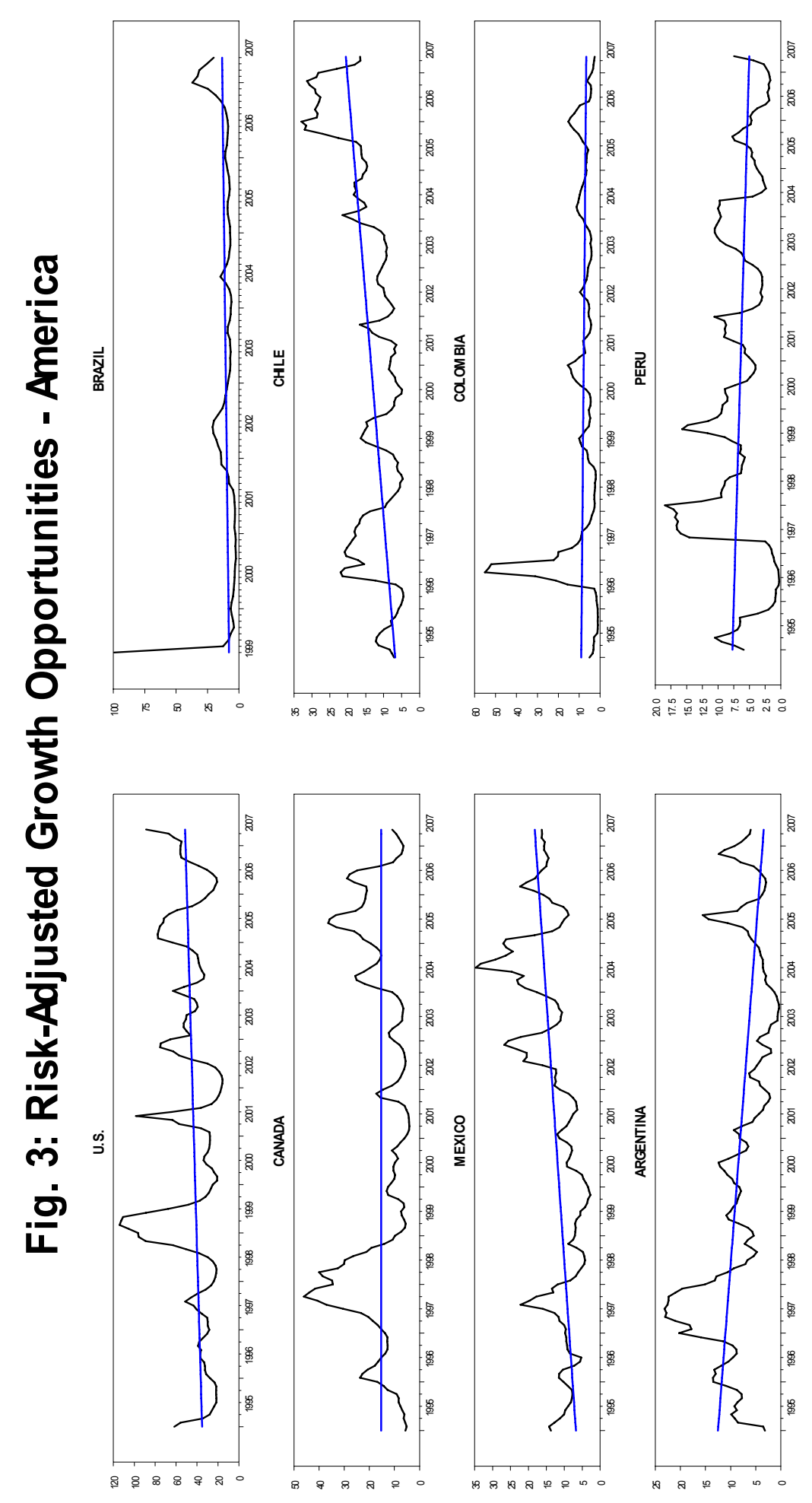




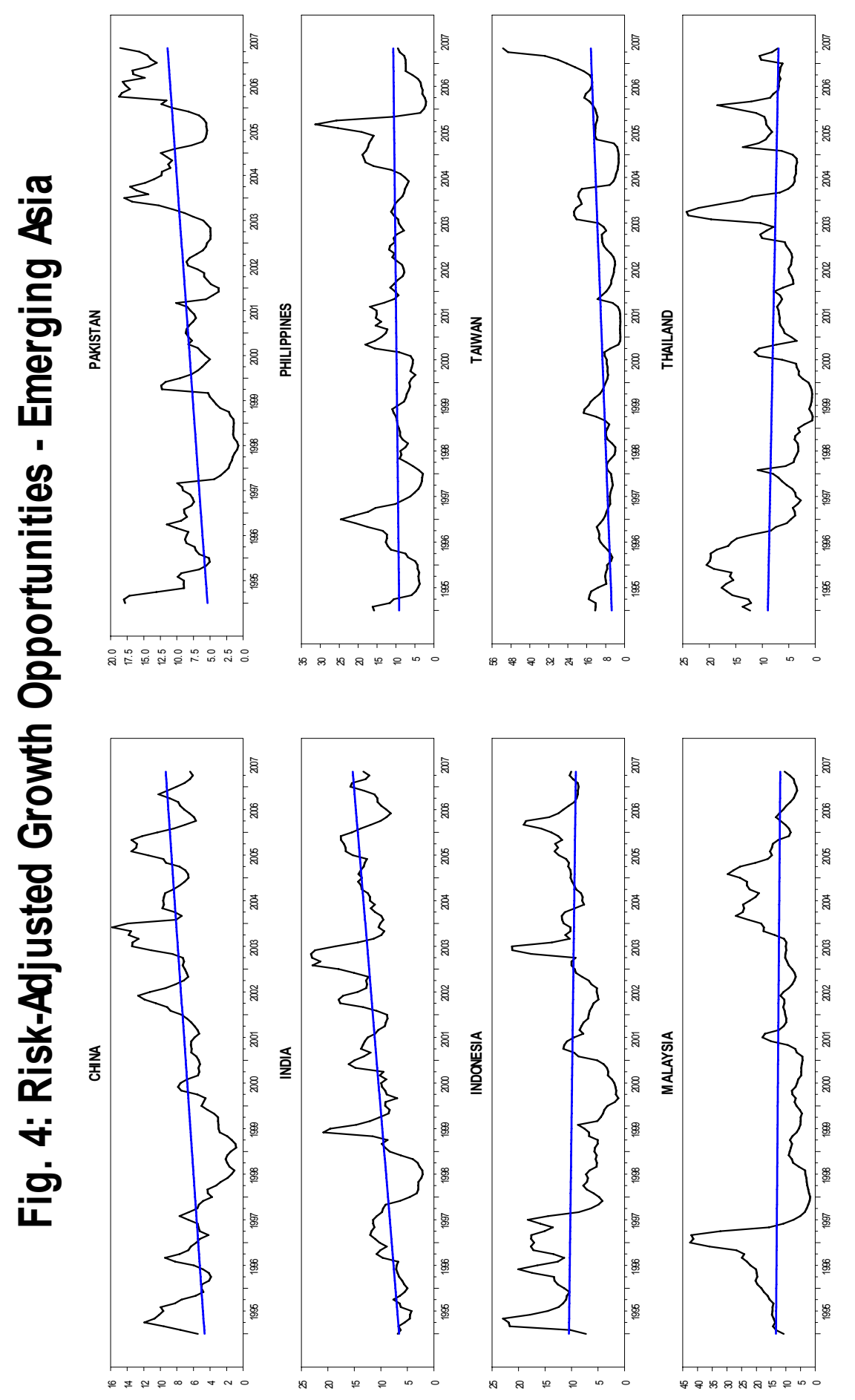

